\title{
Analytical Study of the Cable-Truss Systems on the Glass Certain Walls with Vertical Uses
}

\author{
Yasemin Mesda \\ Department of Architecture, Faculty of Fine Arts, Cyprus International University, Nicosia, Cyprus \\ Email: yaseminmesda@gmail.com
}

Received June 6, 2013; revised July 6, 2013; accepted July 13, 2013

Copyright (C) 2013 Yasemin Mesda. This is an open access article distributed under the Creative Commons Attribution License, which permits unrestricted use, distribution, and reproduction in any medium, provided the original work is properly cited.

\begin{abstract}
The aim of this study is to analyze of the cable-glass systems which are used on the glass curtain wall according to their types, degree, architectural and structural effects. The suspended glass system with pre-stressed cable truss (SGSPCT) is widely started to apply after the 1980's with Serres building. The advantages of these systems are to provide the transparency on the façades and speedy construction process with minimum materials. The disadvantages are: more expensive than other systems and so many details for the joints and load distribution calculations. There are three different architectural design typologies of the SGSPCT system. These are distance bridging systems, between floor system and independent body. These three different typologies can be seen on the same building at the same time. This system has been known as complex structure systems. The twenty five glass buildings which are designed in different systems have been analyzed during this study. After these analyses the five glass buildings which are designed with cable-truss system have been selected for scope of the study. These selected buildings have been included of three different cable-truss system typologies and degree. The methodology of this study is literature survey and building analyses method. The written and visual documents involve books, theses, reports, articles, magazines, drawings, internet sources and applied connection details of the glass buildings. The selected five glass buildings have been detailed analyzed with their architectural drawings, photographs and details. The study consists of five chapters including the introduction chapter. The general information of the glass building and cable-glass system has been mentioned in the first chapter. The structural features, details and analytical information on systems have been explained of the selected buildings in the second chapter. The detailed analyses of these selected buildings have been done according to their schematic drawings with the plans, sections and load distribution in the third chapter. The fourth chapter is discussion section. In this section, cable-truss systems have been compared with their advantages and disadvantages to the other systems. The fifth chapter is the last chapter, many advantages of cable-truss systems have been concluded that the use of glass substrates.
\end{abstract}

Keywords: SGSPCT; Cable-Truss System; Tension Structure; Types of the Cable-Truss System; Glass Curtain Wall

\section{Introduction}

In earliest times, openings were created in the walls of the buildings to allow daylight to enter. Later, the use of the glass for the windows allowed the penetration of daylight while affording protection against the weather. The early glass making techniques of the Middle Ages placed limitations on the uses of glass with very small size openings [1]. With progressive improvements, new architectural design criteria and technology in glass-making techniques and structural characteristics are started to change. These criteria are represented to the progress of the glass using on the façades, a big opening, new dimensions, transparency, light, airiness of spaces, smooth surface and communication between inside to the outside. The frame systems which are carrying of the glass change and development according to the glass dimensions on the façades, roofs and grounds. The wooden frames are changed of metal and steel frame one. Because the openings started to become bigger, the steel frame, truss system, reinforced concrete and cable systems have been used on the glass system at the same time for stronger. The glass material can be used on the façades, roofs, floors and domes.

The curtain wall is one of the typology of glass surface. It is non-structural; it does not carry any dead load weight from the building other than its own dead load weight. The wall transfers horizontal wind loads that are 
incident upon it to the main building structure through connections at floors or columns of the building. It can be made of a lightweight material reducing construction costs, taking into consideration design requirements such as: thermal expansion and contraction, building sway and movement, water diversion and thermal efficiency for cost-effective heating, cooling, and lighting in the building [2].

Crystal Palace (1851), the Glass Pavilion (1914), the Villa Savoye (1931), the Palm House at Bicton (1820) are the most important glass buildings in the glass material development. The Crystal Palace is the first industrial achievements of mass production and the technical feats; the Glass Pavilion is the didactic representation of all the glass materials on the wall, floor, dome and staircases. The very interesting non-planar transparent surface can be seen with curved bay in the Villa Savoye. The Palm House is a green house with transparent surface. The glass and glazing bars form a very delicate skin and the primary supporting structure is being reduced to the absolute minimum [1].

Oriel Chambers (1864) and 16 Cook Street (1866), both built in Liverpool, England, by local architect and civil engineer Peter Ellis, are characterized by their extensive use of glass in their facades (Figure 1). Towards the courtyards they even boast metal framed glass curtain walls which make the two of the world's first buildings to include this feature. The extensive glass walls allowed light to penetrate further into the building utilizing more floor space and reducing lighting costs in short winter months [3].

Curtain wall systems are typically designed with extruded aluminum members or steel. The first curtain wall installed in New York City, in the Lever House building (Skidmore, Owings and Merrill, 1952), was glass mullion system. The Bauhaus in Dessau (1926) and the Hallidie Building in San Francisco (1918) are earlier modernist examples in glass curtain wall [2] (Figure 2). In Dessau as in Alfeld, the glass curtain wall suspended in front of the load-bearing framework defines the exterior of the workshop wing and openly shows the constructive elements [5].

Curtain walls can be classified by their methods of fabrication and installation into the following general categories: stick systems and unitized (modular) systems. In the stick system, the curtain wall frame (mullions) and glass or opaque panels are installed and connected together piece by piece [7]. Unitized curtain wall is an exterior façade system for high-grade buildings that matches the current international trend. With the integrated advantages of factory assembly, highly standardized technologies and greatly shortening construction period, it has been the most popular curtain wall with the most developing advantages in the field of curtain walls [8].

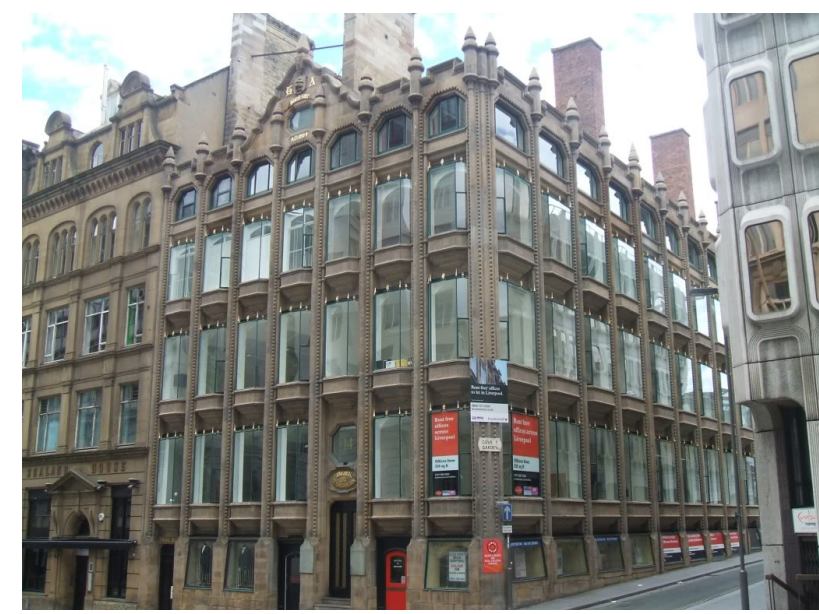

Figure 1. Oriel Chambers, Liverpool, England, 1864 [4].

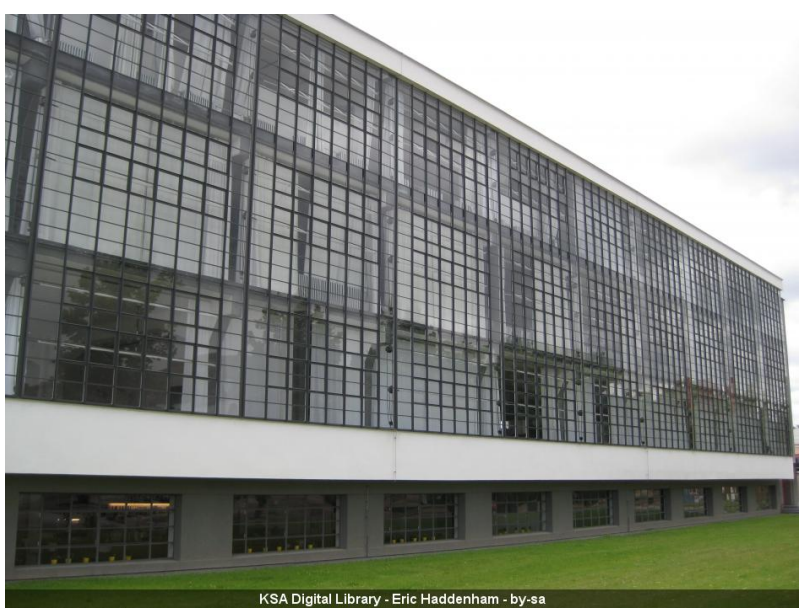

Figure 2. Glass curtain wall of the Bauhaus Dessau, 1926 [6].

The Serres were also to remain unchanged both in design and architectural function. The project architect, Adrien Fainsilber, defined the Serres as a transition space between the building and the park and wanted them to be as light and transparent as possible. The technical character of the Serres is architectural style called high-tech [1].

The advantages of the cable truss curtain wall systems are to provide the transparency and reflection on the façades, light surface, functional, speedy construction process with minimum materials, distinct social benefits, flexibility, strong adaptability for displacement of the main structure, no need to apply sealant on site, no influence of weather situation, meeting high requirements of environmental protection and energy saving [8]. The disadvantages are more expensive than the other systems and so many details for the joints, load distribution calculations, safety. This system needs to be correctly engineered, carefully detailed, accurately fabricated and properly installed [9]. The system is created minimization of 
the supporting elements and maximization of the transparency.

The load calculation, air infiltration, water penetration, deflection, strength, thermal criteria and safety are the most important features during design and construction of glass buildings [2].

This paper contains five chapters. The general information of the glass building and cable-glass system has been mentioned in the first chapter. The architectural and structural analyses have been explained of the 25 buildings in the second chapter. The detailed analyses of 5 selected buildings have been done according to their schematic drawings with the plans, sections and load distribution in the third chapter. The fourth chapter is discussion section. In this section, cable-truss systems have been compared with their advantages and disadvantages to the other systems. The fifth chapter is the last chapter, many advantages of cable-truss systems have been concluded that the use of glass substrates.

\section{Architectural and Structural Analysis of the Cable Glass Structures}

The 25 buildings have been analyzed according to the level of complexity, structural hierarchy, geometry, architectural design typology, integration and existing of new details before this study. The level of complexity and architectural-structural design typologies has been analyzed scope of this study.

These 25 buildings have been examined of four different criteria according to the architectural characteristics. These are: distance bridging system (DBS), between floor system (BFS), independent body (IB) and complex structure (CS). These different criteria are affected for selected of the 25 building. The above mentioned four typologies can be seen of these selected 5 building. The cable truss glass system is designed certain distance of the main building structure in the distance bridging system. The glass surfaces are located between the floors in the between floor system. There is no distance between the main building structure, roof and floor. If the glass is no relationship between the main structures in building this system is known as the independent body. These two or three systems are seen on the complex structures in the same time. The cable glass system and steel truss system has been seen in three systems; steel framed structures, reinforced concrete systems, tubular system, SGSPCT, cable-truss system and glass curtain wall can be seen in the complex structures at the same design.

These 25 building have been analyzed according to the structural systems, too. These classifications have been analyzed with degrees. The level of the complexity is classified in the six degrees. These groups are given below [10]:

- First degree: This group consists of cables, glass and tubes. It is the simplest system. Cables are connected with the tubes which makes cable trusses.

- Second degree: This group likes as Serres model. There is a vertical on the same plane with the cable truss.

- Third degree: Instead of truss, there are cables which are connected to the main building structure.

- Fourth degree: Certain degree of integration between the main building structure and the suspended system.

- Fifth degree: It uses of complex geometries.

- Sixth degree: Two different types of integration coexist.

The architectural and structural classification has been given in Table 1.

5 buildings are the first degree, 6 buildings are the second degree, 8 buildings are the third degree, 5 buildings are the fourth degree, and one more is the sixth degree in scope of this study. 10 buildings are distance bridging system, 6 buildings are between floor systems, two of them are the independent body and 7 buildings are complex structure according to their architectural characteristics.

\section{The General Information of Selected Five Buildings}

The general information has been given in chapter 2 of the 25 building. After that, 5 buildings have been selected and analyzed in detailed in this chapter. The architectural design criterion is the important factor for to select these 5 buildings. The buildings have been selected in the same group in terms of structural features.

Intent of the study, the effects have been analyzed which are the same structural system building and different architectural design typologies in the aim of this study. The vertical cable-truss and inside using can be seen on the selected 5 buildings' façades.

1) Quay Grand Circular Key

This building has been constructed in 1999 in Australia. The architectural project group is PTW Architects. The function of the building is residential and commercial. Steel, cable, glass and reinforced concrete are the main structural materials of this building. Many of these spaces are enclosed by operable glass screens, which can be opened in suitable weather, providing strong visual and physical links with the surroundings. The upper level penthouses enjoy panoramic views [11].

The main elements of the public domain are the colonnade, promenade and through-site access points. The scheme links the widened Macquarie Street with accessible paths of travel to the water and the glass and steel canopies at the north and south ends, which provide undercover access from Circular Quay to the Opera House [11].

The between floor system has been used of this build 
Table 1. Classification of the buildings.

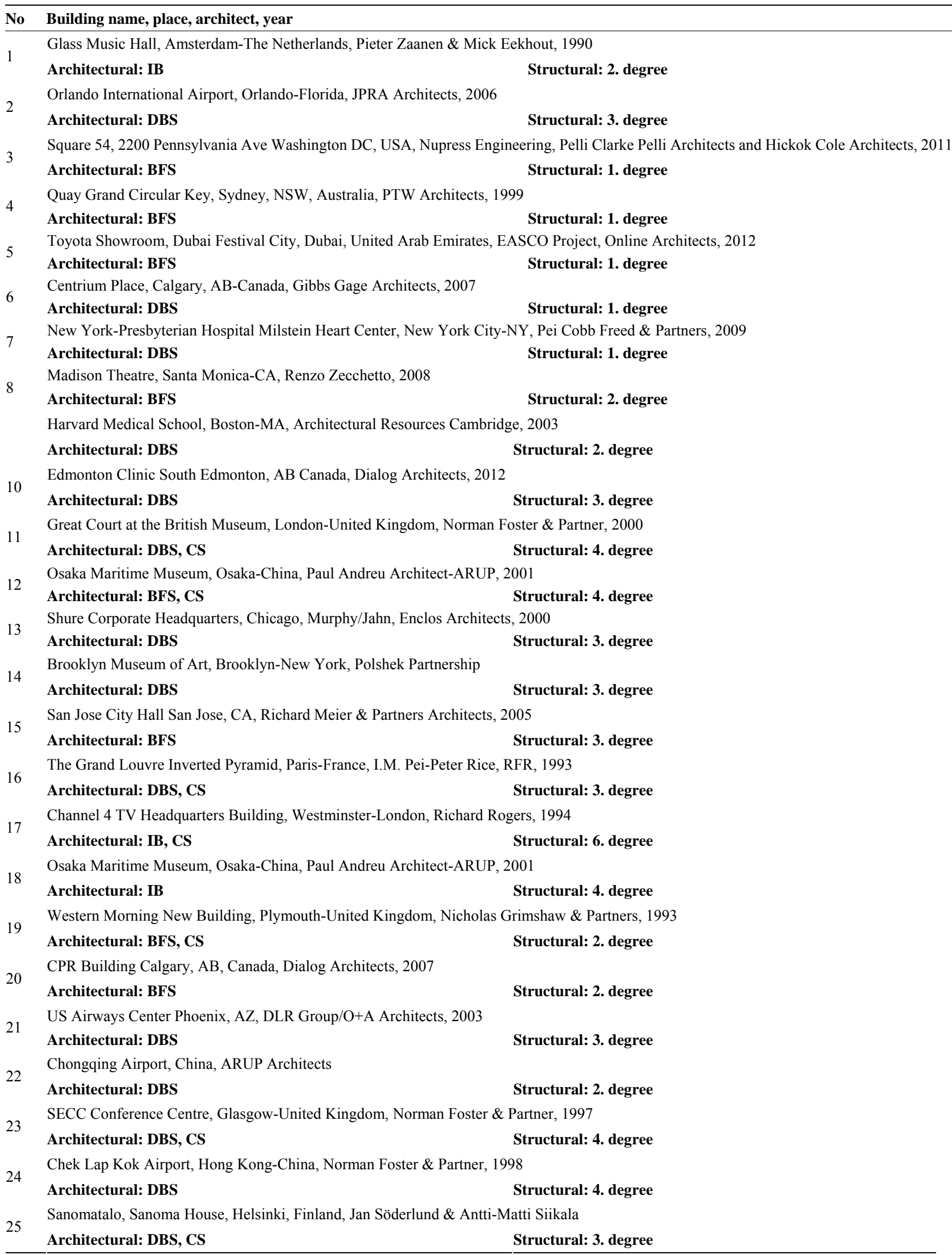


ing. The degree of the building is first, because of the system consist only the cables, glass and tubes as simplest one (Figure 3).

2) Toyota Showroom, Dubai Festival City

This building has been constructed in 2012 in Dubai, United Arab Emirate. The architectural project group is EASCO Project, Online Architects. The one storey building's function is commercial. Steel, cable, glass, metal and reinforced concrete are the main structural materials of this building.

Architectural Lighting Control System in car showrooms and Lexus cafe. Control is around 800 channels of architectural lighting and a show area in each car showroom. The show area incorporates DMX show lighting, turntable control and an audio system, controlled by a purpose-built system. Customized touch screen in each showroom with several programming points provides manual override for scenes and control over pre-programmed shows [14].

The system of this building is between floor system and first degree (Figure 4).

3) New York-Presbyterian Hospital Milstein Heart Center

This building has been constructed in 2009 in New York. The architectural project group is Pei Cobb Freed \& Partners.

This hospital addition, inserted between two existing hospital buildings, is enclosed by a four-story doubleskin glass façade adjacent to a four-story-high atrium with point-supported glass walls and a skylight. Glass floor bridges connect it to the existing buildings on its three upper levels. Each of the addition's two entries employs its own glazing system: captured insulating glass units and an austere glass canopy mark the 165th Street entrance, while visitors entering at Fort Washington Street pass through an all-glass vestibule backed by a

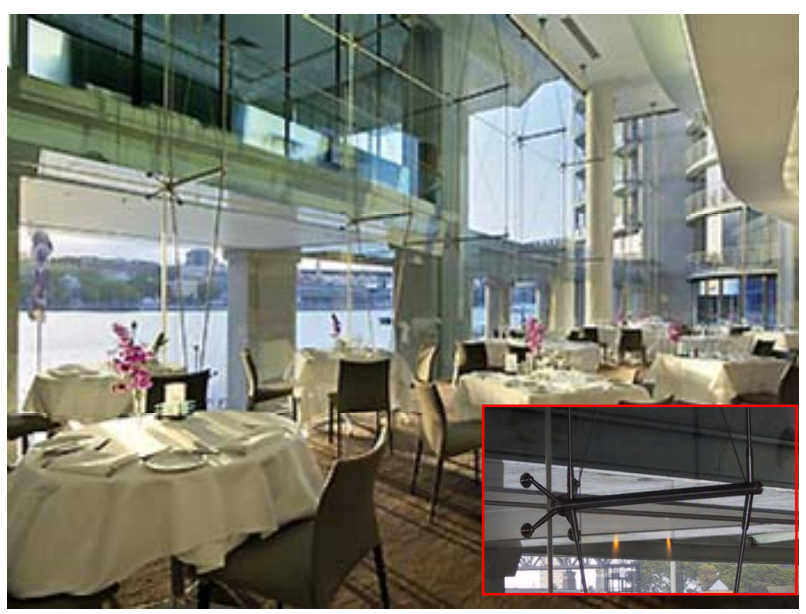

Figure 3. The general view and detail of the Quay Grand Circular Key [12,13]. cable truss wall with point-supported glazing [15].

Steel, cable, glass, metal and reinforced concrete are the main structural materials of this building. The system of this building is distance bridging system and first degree (Figure 5).

4) Harvard Medical School

This building has been constructed in 2003 in Boston. The architectural project group is Architectural Resources Cambridge. The function of the building is educational. Steel, cable, glass, metal and reinforced concrete are the main structural materials of this building.

The curtain wall system was installed on the exterior façades. Curtain wall designs for the complex tower facade program were developed by Enclos to provide ample daylight and flexible, open laboratory spaces. Multiple story sky lobbies and split-level communal areas feature clear glass facades with sprawling views of downtown Boston. Cable truss supported glass walls wrap the entire 4-story lobby and conference area at street level. The cable truss system is comprised of a series of regularly spaced pre-stressed vertical cable trusses at five feet

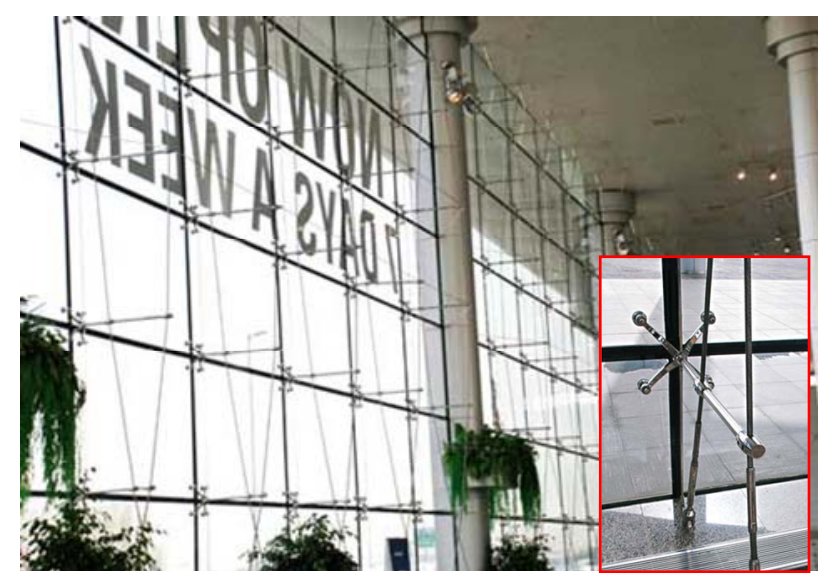

Figure 4. The general view and detail of the Toyota Showroom [14].

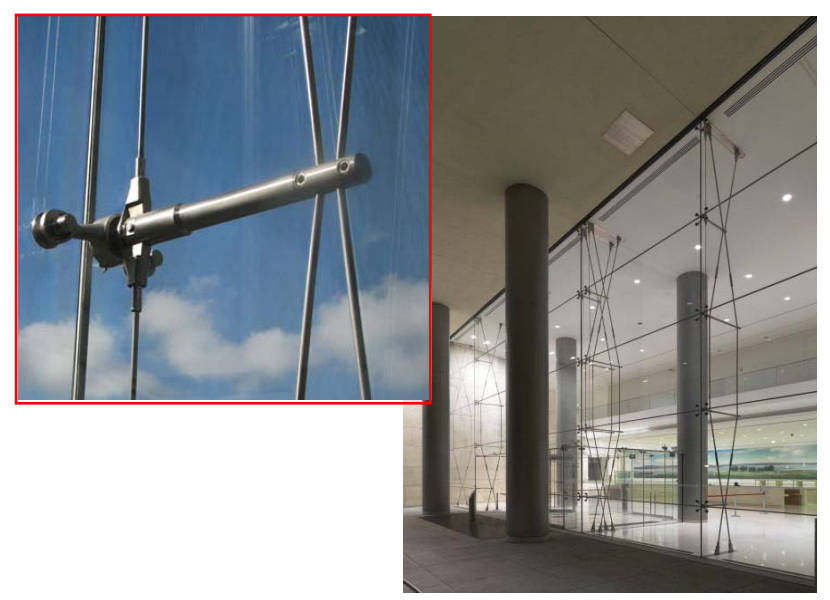

Figure 5. The general view and detail of the New York Presbyterian Hospital Milstein Heart Center [15]. 
on center, supporting a point-fixed glazing system [16].

The system of this building is distance bridging system and second degree (Figure 6). Second degree group likes as Serres model. There is a vertical steel structure on the same plane with the cable truss.

5) Edmonton Clinic South Edmonton

This building has been constructed in 2012 in Canada. The architectural project group is Dialog Architects. The function of the building is healthy. Steel, cable, glass, metal, stone and reinforced concrete are the main structural materials of this building.

One of the design challenges was to create an interactive learning environment in a building that runs the length of two football fields. The color-coded floors and clear organization help users navigate the space. A northsouth building "main street" filled with natural light links to walkways, plazas, cascading stairs, elevator banks and exit stairs. Edmonton's harsh climate demanded a highperformance envelope and aggressive energy recovery systems. High-performance glass, diffusing films, brise soleils and reflectors help control the natural light. A green roof and the use of native vegetation reduce storm water runoff and minimize irrigation needs [18] (Figure 7).

The system of this building is distance bridging system and third degree. Third degree is instead of truss, there are cables or tubes which are connected to the main building structure.

\section{The Detailed Analyses of Five Selected Buildings and Discussion}

The schematic plan and section has been drawn in Figure 8. The building structural affects have been changed related to the different architectural design criteria. An example of a frame using a tension structure is shown in Figure 8. The tension system represents frames primarily

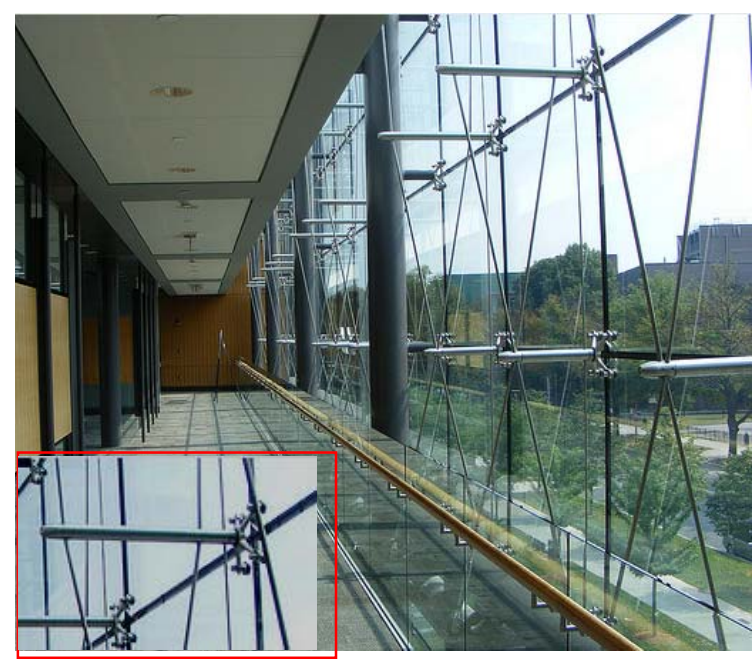

Figure 6. The general view and detail of the Harvard Medical School [17].

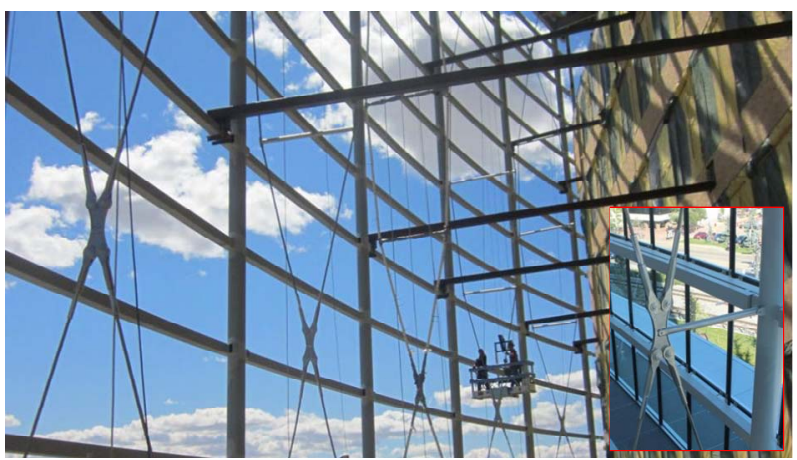

Figure 7. The general view and detail of the Edmonton Clinic [19].

supporting a fixed load and live load, or so-called dead load.

The main structural members are glass, cable, strut, spider, tube, fitting, main building structure, preliminary and secondary structure is analyzed on these buildings during this chapter. The tension structure is an excellent structure type that not only produces a highly aesthetic space but also functions as a main structural member capable of withstanding earthquake and strong winds since an extra axial force is introduced thereto artificially [20].

The pre-stressing serves for the rigidity of the system in the lower load ranges. Pre-stressing the tie rod results in compression in the horizontal member, compression that grows with the increase in tension is shown in Figure $9[10]$.

\section{Conclusions}

The architectural glass material has been used on the façades, floors, roofs, domes and staircases of the buildings since the 1800s. The main aims are lighting, transparency, visual quality and connection of the glass using on building design. The different glass building structures and typologies are started with improvement technology and changing architectural designs.

The glass building can provide the transparency, light surface, speedy construction process with minimum materials. Furthermore, this system needs many details for the joints and load distribution calculations. It is more expensive than the other systems and it has a safety problem in some conditions. This system needs to be correctly engineered, carefully detailed, accurately fabricated and properly installed.

The third degree system is the most using complexity level according to the results obtained from 25 analyzed buildings. According to this system, there are cables which are connected to the main building structures. The ground and roof connection details are generally the same of these buildings.

Main building structure does not affect the complexity. 
(a) Quay Grand Circular Key

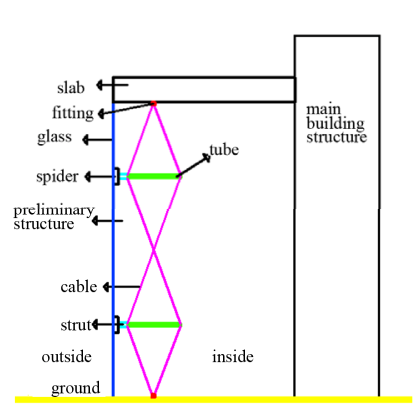

(c) New York-Presbyterian Hospital Milstein Heart Center (b) Toyota Showroom, Dubai Festival City

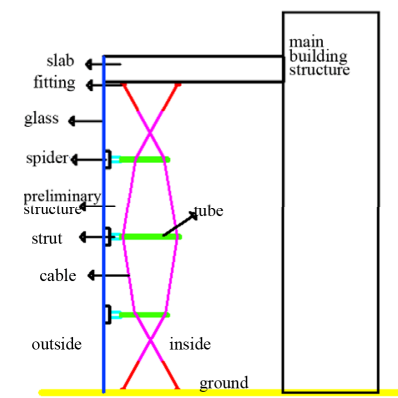

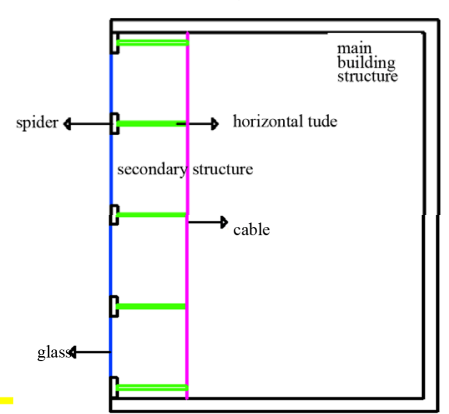

(d) Harvard Medical School
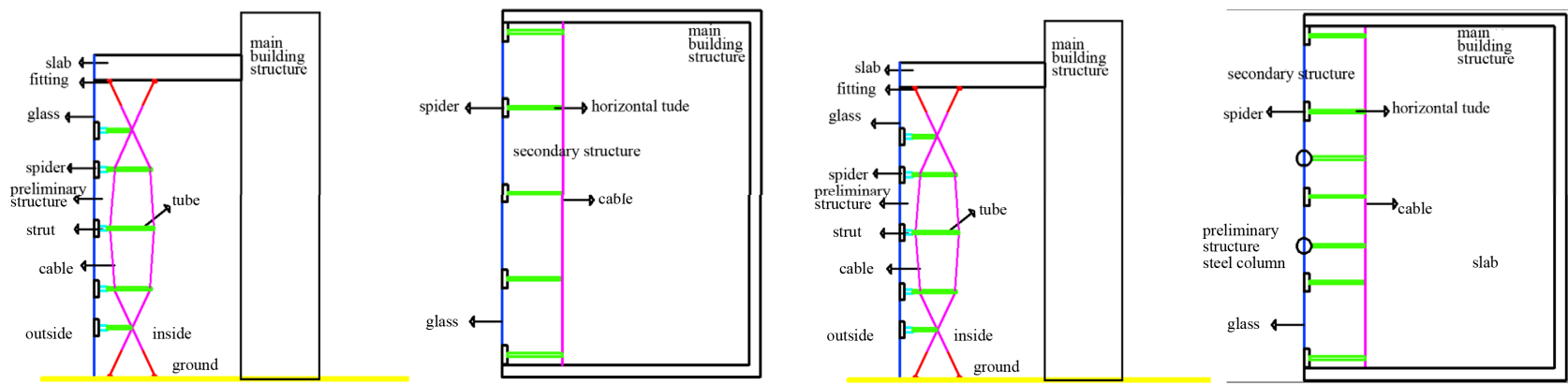

(e) Edmonton Clinic South Edmonton
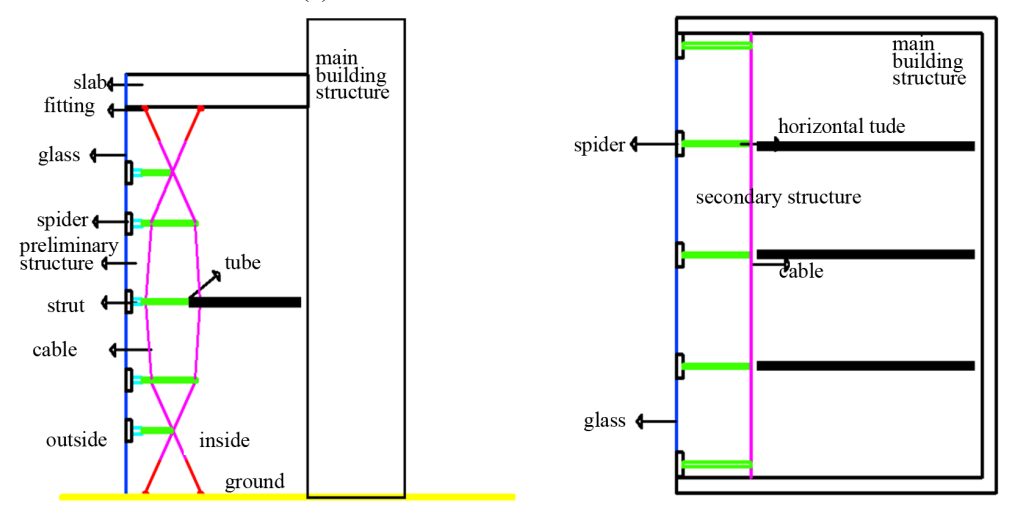

Figure 8. The example of the cable-truss structures with the selected five buildings

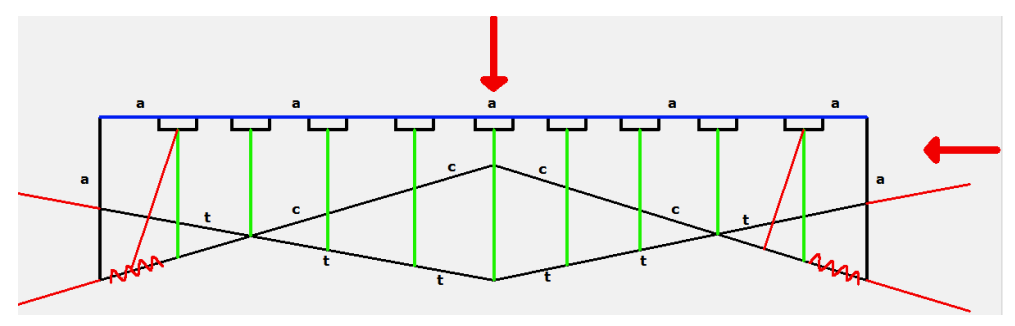

Figure 9. The cable truss system load analysis.

The cable truss system can be changed according to the main building shape and architectural effects. If shape of the main building is rectangular, the degree of the building is first. If shape of the main structure is circular or rectangular, the degree of the building is second. Third degree building has circular or parabolic plan geometry.

In the bright future the relation between the process of design and the interaction between buildings will be achieved in just one step. This is a whole interaction which is able to lead to a design and a designed-interactive object. This may become a reformulation of what is understood as architecture and maybe, even the name will change to express the new-powerful condition of being an architect. New architecture, new complex ge- 
ometries and material evolution do not exclude the conventional materials that have been used forever in construction, such as concrete, timber and bricks. The research shows that there are additional new details, new processes that evolve the ways which all types of materials have been used in the last years [10].

\section{Authors and Affiliations}

Yasemin MESDA was born on 11.11.1988 in Nicosia, Cyprus. She was especially interested in restoration, preservation and history of architecture. She studied at Cyprus International University for graduate and M.Arch. She is started to study Ph.D. study. She is research assistant at Department of Architecture at Cyprus International University, Nicosia, North Cyprus until 2010.

\section{Acknowledgements}

The author would like to thank Cemil ATAKARA for his patient advice, criticism and discussion throughout the writing process.

\section{REFERENCES}

[1] P. Rice and H. Dutton, "Structural Glass," E\&FN Spon Printing, London, 1995.

[2] www.en.wikipedia.org/wiki/Curtain_wall

[3] http://www.orielchambers.co.uk/\#/411

[4] www.adventimforarchitects.wordpress.com

[5] http://www.bauhaus-dessau.de/index.php?The-bauhaus-b uilding-by-walter-gropius
[6] https://ksamedia.osu.edu/

[7] http://www.wbdg.org/design/env_fenestration_cw.php

[8] http://www.janghogroup.com/html/2009/0608/192.html

[9] http://www.structuralglass.com/tss.html

[10] C. Atakara, "Determining Factors of Complexity in Structures," Ph.D. Thesis, Institute of Graduate Studies and Research, EMU, Gazimağusa, Cyprus, 2010.

[11] http://www.e-architect.co.uk/sydney/east_circular_quay.h tm

[12] http://www.accorhotels.com/gb/hotel-8779-pullman-quay -grand-sydney-harbour-prev-quay-grand-suites/media.sht ml\#photo

[13] http://www.nupress.com.au/gallery/?album=1\&gallery=21

[14] http://www.lisus.com.sg/2006d.html

[15] http://www.heintges.com/project.php?id=ny-hospital-hear t-center

[16] http://www.carboline.com/media/88036/Havard\%20Medi cal\%20School.pdf

[17] http://www.flickr.com/photos/stevenwbuehler/415302619 4/

[18] http://www.hok.com/design/type/education/edmonton-cli nic-health-academy-/

[19] http://www.stellaglasshardware.com/project/kaye-edmont on-clinic

[20] A. Tomimoto, et al., "All Development of NS Tension System for Space Frame," NIPPON Steel Technical Report No. 92, 2005. 